\title{
GRANMATICAL ANALYSIS OF INTERLANGUAGE
}

\section{Kim Barker}

\author{
University of Cambridge \\ Maskew Miller Longman
}

\section{ABSTRACT}

The process of second language acquisition involves the active construction of "interim grammars" or "interlanguages" (Selinker, 1972) by learners as they progress towards competence in the target language. An interlanguage evolves as a result of the various strategies which learners apply to the

- : task of language learning. The primary aim of this study was to analyse and describe the interlanguage of two second-language English speakers in samples of interactional spoken language with the goal of identifying the learning strategies being applied and developing appropriate, empirically based intervention strategies designed to facilitate the acquisition process. A secondary aim of the study was to evaluate the appropriacy of the particular descriptive tool employed in this study, namely the Language Assessnent, Remediation and Screening Procedure (LARSP) (Crystal, Fletcher and Garman, 1989), in the context of L2 acquisition research.

While the LARSP provided a useful inilial description it lacked precision in identifying and accounting for the numerous error patterns produced. A detailed error analysis was therefore devised which permitted identification of idiosyncratic strategies as well as the more general error patterns that characterised the interlanguage of both subjects in strikingly sinilar ways. Of particular note was the finding thal the acquisition of the verb phrase and its components was particularly problematic for both subjects. Numerous errors in the realisation of the argument structure of lexical verbs was noted. As it is generally agreed that the verb phrase plays a central role in the syntactic organisation of the sentence and contributes significantly to communicative efticiency (Fletcher, 1992), this finding has significant implications for second language pedagogy and warrants further investịgtion

\section{INTRODUCTION}

Educators in South Africa currently face a crisis that is by no means unique world-wide but for which they are largely unprepared. The int egration of South African schools has resulted in a submersion-type siluation where many pupils are being educated through the medium of English when they have had mirimal prior exposure to the language and therefore display extremeily limited proficiency.

As language constitutes the primary medium of most aspects of formal education in Western culture ( Van Kleecli and Richardson, 1988) limited proticiency in the language of instruction places a child at a disadvantuge which may result in academic difticulties. 
In order to avoid such a disadvantage and promote the development of bilingualism, it is postulated that a minimal or "threshold" level of linguistic contpetence is required in both languages (Cumnitis, 1976) It has therefore been argued that teaching of the second language (L2) should not be commenced until the first language (L1) is properly consolidated. However, it is not clear at what point in the development of the L1 such a threshold or degree of consolidation can be said to have been achieved (Makoni, 1993).

The first important factor in avoiding academic disadvantage therefore appears to be maintenance and enlancement of LI skills (Cumnins, 1991) while the second is the facilitation ... of L2 acquisition. Makoni (199.3) suggests that the acquisition of English by African pupils does not have any negative impact on the retention of their home languages as they are used in "functionally different domaıns, English is highly valued for instrumental purposes in educational contexts and African languages are perceived as languages of the home and hearth" (p.91).

Thus, while ongoing developmenl of the indigenous languages is essential, it is the second factor that requires the urgent attention of educators However, the identification of difficulties that L2 learners are experiencing in acquuiring English and the development and implementation of appropriate intervention strategies to facilitate and enhance the acquisition process, need to be bascd on enpirical evidence. It is felt that such evidence can only be obtained through careful and comprehensive investigation of the $L 2$ acquisition process in learners from the particular population of concern.

The motivation for providing comprehensive descriptions of the sequence of development of linguistic structures in the $L 2$ is based on an approach to the learnability of language espoused by Pienemann (1989) and Schmidt-Schonbein ( 1988 cited in Dirven, 1994) amongst others, who believe that psycholinguistıc constraints deternine the hierarchical emergence of language structures. They believe that structured formal input which is in advance of the subject's developmental acquisition level is at best, ineffective and at worst, detrimental to the development of the L2 (Duncan, 1989. McLatughlin and Robbins, 1994). Information regarding the expected sequence of cievelopment of the $L 2$ is therefore necessary in order for appropriate grading of structures in syllabu as svell as for accurate selection of appropriate teaching goals for particular groups of learners 
The process of acquisition has been characterised as involving the active construction of "interim granmuars" or "interlanguages" (Selinker, 1972) by learners as they progress towards the carget language. An interlanguage is thought to evolve as a result of the various strategies which learners apply to the task of language learning in order to "make sense of input and "control their own output" (Mcl.aughlin and Robbins. 1994, p.3478). McLaughlin and Robbins (1994) propose that we can learn a great deal regarding the nature and systematic properties of the learner's interlanguage by making a series of descriptions of learners' language usage $($ p. 3749$)$.

\section{METHODOLOGY}

\section{$2.1 \quad$ Aims}

.. The primary aim of zhis study was to analyse and describe the "interim grammars" or - interlanguages used by two second-language English speakers in samples of interactional spoken language. The subjects are undergning their first year of primary education with English being the medium of instruction. Both subjects are first language Zulu speakers who have had linited prior exposiure to English. (For detailed subject description see Appendix 1). As this appears to be the first attempe which has been made 10 describe the interlanguage of this particular population of tearners, the study was necessarily exploratory

A sub-aim of the study was to evaluate the usefulness and appropriacy of the particular descriptive tools used in this study in the contest of second language acquisition research

\subsection{Why LARSP?}

The tool selected for the initial analysis and description of the language samples was the Language Assessment. Remediation andi Screening Procedure (LARSP) developed by Crystal, Fletcher and Garman (1976. 1989) which is based upon the appioach to grammar described by Quirk. Greenhaum, Leech and Siartvik (1972, 1985). The procedure involves elicitation, transcription and linguistic analysis of a sample of incractional spoken language. 
Findings are summarised on a protile charn on which linguistic categories have been graded developmentally into seven discrete stages according to research in normal child language acquisition

A LARSP protile does not constitute a statement of the subject's ability but simply summarises theis performance in a particular situation. The analyst is required to infer further information by interpreting the chart in the context of the transcription on which it was based (Crystal, 1992)

The selection and use of this procedure is motivated on the following grounds:

- LARSP provides a frametvork tor descripsion in a context where culturally appropriate language assessment toois based on locally derived norms of development are virually non-existent and linguistic research is traught with difficuities as a result of the multilingual nature of the target population.

- LARSP profiles the emeryence of syntactic and morphological structures in language development. It has been suggested that the assessment of morphosyntax may yield the clearest indication of the developmental level of an individual interianguage ( $\mathrm{Clahsen}$, 1985).

- LARSP encourages systematic and delailed appraisal of language samples, organising data in such a way that emerging patterns can be identified (Crystal, 1992).

- It is claimed that the whole range of adult syntactic structures in English can be analysed within the descriptive lramework of L.LRSP (Clahsen, 1985)

- McLaughlin (1984) and Duncan (1989) refer to numerous studies which have found that "emerging morphology and syntax secus to develop in a similar pattern in both first and second language English, in primary school aged children with mother tongue and gender not presenting as significanl variables" ( $p$ | 3 ) Although this tinding is not without its exceptions, Duncan (1989) belicves that it justifies the use of descriptive development profiles of the structure of 1.1 English to chart the morphosyntactic development of L2 English. 


\section{PHASE 1: RESULTS OF LARSP ANALYSIS}

(A glossary of the symbols used in the LARSP is provided in Appendix 2).

The LARSP profiles of both subjects reveal striking similarities between the nature and level of their acquisition of English syntax

\subsection{Clanse Structure}

Both subjects:

- appear to have mastered syntactic structure up to Stage III as evidenced by the wide distribution of clause and pluase types produced at this level.

- produced Stage II and Srage III clause element expansions indicating their ability to integrate clause and phrase structure

- have well-established English word orter palterns

- used very few constructions with douhle objects

- produced feuv Stage IV clause structures

- produced numerous co-ortinated and subordinated Stage V constructions. The existence of "islands" of proficiency at Stage $V$ and higher stages makes accurate appraisal of subjects' abilities at these levels problematic. LARSP is acknowledged to be less reliable at the more advanced stages due to increasing variability between learners and a lack of research support (Crystal et al, 1989)

- displayed overuse of contectives cand and other in relation to the number of co-ordinated constructions used. (The connective coded as esher on the profile was the adverbial connective $t / \kappa^{\prime} i$ )

Very few Stage VI and VIS structures were noted in HD's sample. \#L produced a slightly wider range of Stage $V / I$ stuctures including two instances of nore advanced noun phrase co-ordination patterns 
\# $\mathrm{L}$ used complex complemturation in four utrerances which would seen to indicate a relatively advanced level of language development. However, Ellis (1985) stresses the importance of distinguishing berween formulaic utterances characteristic of early $\mathrm{L2}$ acquisition and "creatively constructed utterances" (p.167) when assessing children acquiring an L2. There is a danger of accepting formulaic "chunks" as prenature evidence of the child's level of proficiency (Jordaan, 1993). Several of \#L's constructions were only prevented from being coded as stereotypes by her use of varying intonation patterns and accompanying gestures. It is likely that these represent structures over which she has not yet established complete control. The area of complex complementation is felt to be such an area. All instances of this structure were of the form $h k^{\prime}, Y$ and while they were contextually appropriate this structure was clearly limited in scope.

\subsection{Plarase Structure}

\section{Both subjects}

- produced a representative range of phrase structures at Stages II and III

- used a Iarge number of personal pronouns but displayed numerous errors of pronominal reference.

- used a significant number of ofher auxiliaries. despite \#L's frequent omissions of this structure. The most frequent contex of tsage of auxiliaries by both subjects was in the present progressive construction This also resulted in the dispropontionately frequent occurrence of the morpheme-ing. The progressive aspect was frequently overused in inappropriate contexts by both subjects

- produced few Stage iV phrase structures although each subject displayed an isolated strength at this level \#L produced numerous examples of $X c X$ constructions, \#D produced several examples of $N_{c}, \mathcal{V}$ which was consistently realised as auxiliary + contracted negative + vorb stem

\#L produced a single post-modifying clause (Stage $\mathrm{V}$ phrase structure) in object position. 


\subsection{Word Structure}

Frequent occurrence of the morpheme -img in both samples has been discussed

Subjects produced a wide range of the morphemes coded under word structure, although several significant gaps were evident. Both subjects used very few past tense forms and neither produced any past participles. This lighlights a striking feature of both samples, namely the virtual absence of past tense fornis and an abundance of uninflected verb forms. Neither subject displayed any means of referring to past time. using only unintlected bare verb stems or progressive aspect (apart fiom isnlated occutrences of past tense forms).

\#L produced more 3ragreement markers !han \#D who seemed aware that the markes/s/ was required but displayed inconsistency in selicting the appropriate position for its insertion into the utterance. In scveral examples a contracted auxiliary appeared to have been inappropriately inserted between the subjest and an uninflected verb form but these may in fact have been aftempts to achicve $3 . s$ agleemsnt

\subsection{Stage VI Errors}

Both subjects produced numerous siructures which constituted syntactic "errors" according to the LARSP analysis and which were recoriled in the Stage V1 "Error box". Errors were noted in $54.94 \%$ of flL's utterances and in $58.38 \%$ of HD's utterances. Considering that $26.54 \%$ of \#L's utterances and $22.54 \%$ of "L's utterances were "minor" utterances, only $18.52 \%$ of HL's and $19.08 \%$ of HD's urterances consisted of accurately produced major utterances. Thus errors constitute a central feature of the inlerlanguge produced by the subjecss of this study.

The most frequenlly occurring errors coded for both subjects were:

- Element omission

- Determiner errors

- Personal pronosun entrors

- Preposition errors 
In addition \#L displiayed a high incittence of:

- "Oiher" conneclive usage crrors

- Deterniner onvission

- Auxiliary onission

- Copula errors

Both subjects produced nunerous other syntactic errors that could not be satisfactorily accounted for by the caterories of error classification included on the LARSP.

3.5 Summary: Findings of the LARSP analysis requiring further investigation

\section{BOTH SUB.IECTS:}

- Very few doubje-object constructions (SH) (Od)i

- Underrepresentation of Stage W clause and phrase structure

- Overuse of aml and tho' connectives

- Overuse of progressive aspect

- Absence of pasi tense inllections, overuse of uninflected verb stems

- Errors of element ontssion. determiner selection, personal pronoun usage, preposition selection

- Numerous errors which could not be accurately encoded within the existing "error box" categories

SUB.JECTI

- Auxiliary omission

- Other connective usage ersors

- Determiner onission

- Errors in usage of the copula

- Overuse of "empty" terms and semi-sterentypic chunks

SUBJECT D:

- Auxiliary insertion and'or dlificulty establisting is agreenent

- Few subject expansions - use of pronouns or subject omission

- Few descriptive terms used 


\section{DISCUSSION: FINIINGS OF LARSP ANALYSIS}

The LARSP procedure is felt to have provided a fairly detailed initial description of the interlanguage produced by the two subjects in the samples analysed and has highlighted several areas for further investigation. However, one aspect of the LARSP that was felt to offer an insufficiently detailed analysis of the available data was the Stage VI Error classification. Böh subjects produced an extremely high proportion of utterances containing at least a single error and, more commonly, multiple errors. It should be noted that although the term "error" "will be adopted for the purposes of this paper to refer to the occurrence of any syntactic or morphological feature that is considered unacceptable in the target language, the term is not "used without reservation. It is unfortunate that the term "error" has such negative connotations as errors in this study are viewed as positive evidence of the nature of the subjects' emerging linguistic systems

$=r$

Non-occurrence of a structure in a particular sample cannot be considered evidence that the subject is unable to produce the structure amd even the production of an utterance that is correct by the standards of the target language, tells us very little about its grammatical status However, errors. particulasly systematic errors, may provide "a window on the developing system" (Fletcher, 1985, p. 25). Careful analysis of errors can reveal the strategies that learners are employing in the active construction of their interlanguage and the hypotheses that they are making regarding the target language

(McLaughlin, 1984)

Therefore, a complete description of interlanguage requires that both accurately and inaccurately produced aspects of the interlanguage be accounted for (Hawkins and Spencer, 1985). It is felt that dute to its limited scope. the error classification on the LARSP profile was unable to futtil this requitroment

Crystal et al (1989) indicate that it is only mtended to constitute a first step in the identification of error patterns. However, in the current study it was felt that even as a first step it was limited as numerous widely-occurring and significant errors within both samples 
faited to be accurately accosunted for within the existing cateyories. It is acknowledged that these errors may be particularly clasacteristic of ' 12 learners' interlanguage and were thus not relevant in a profile designed fior the description of disordered language in monolingual English speakers.

For example, the lack of tensed verb forms. overuse of the progressive aspect and other errors in tense marking could nol be coded at all in the current classification, while a category such as "Personal pronoun error" lailed to reveal the particular difficulty that the subjects have with pronoun gender

Previous researchers have also identified limitations in the LARSP error classification, even with respect to disordered tirst language development (Connolly, 1984; Hawkins and Spencer, 1985). Connolly (1984) suggested that either the error analysis should be undertaken as a complementary but separate task to the profile itself or should be distributed more homogeneously along the vertical dimerision of the chart

For the purposes of this studly. a separate extended eiror analysis fornat was devised which more accurately reflected the nature and sange of errors identified. The categories represented on the LARSP probile formed a basis for the analysis and werc modified or supplemented as necessary (with reference to King and Fletcher, 1992). A list of categories included, descriptions of each category and examples of error types is presented in Appendix 3.

\section{PHASE 2: EXTENDED ERROR ANALYSIS}

\subsection{Connectivity}

A striking feature of this section is the high incidence of inappropriate insertion of the adverbial connective thet atter am $/$ in co-sirdinated sentences. In narrative discourse the use of both connectives is acceptablie to indicare the temporal sequence of events described However, \#L overused this device in inap|ropriate contexts. It is hypothesised that she is using and then as a formulaic connective "chunk" without awareness of its semantic implications 


\section{Clause Elements}

$$
\therefore \text {. } \because \text {. }
$$

Both subjects onit a significant nutuber of obligatory clause elements. As these clements constitute the argument structure of the verb it was feit that a more detailed investigation of these omissions would provide insignt into the sulyjects' acquisition and representation of verb structure which is considered by many to be a central task in learning a language (See Section 7 below)

, .

\section{4:3 Verb Plirase}

$\because$ By differentiating between copula omision and ecroneous usage of the copula, the analysis revealed that \#L characteristicaliy omis the copula as well as auxiliary verbs.

- H's previously discussed ditriculties in establishing 3.s agreement are reflected in the

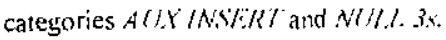

- Three additional calegories chameterise the particular verb errors displayed by these subjects. Both subjects clisplay a high incidence of '/HF' or unintlected verb forms. This, together with their limited auxiliary usige, results in an inability to refer to past time and severe limitations in referering to fiture time.

- Inappropriate overuse of the prosrcssive aspect ( $/ R O(C R / F R R)$ also occurred frequently in both samples. This may be the sesult of transfer or "native language influence" (Odlin, 1989) as $Z$ uhu, which is the first language of both subjects, uses adverbiais to differentiate between the present progressive and the simple present (Grant, 1987) rather than differing forms of the varb itself with the result that these tenses may be confused in English.

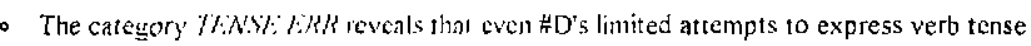
produced numerous errors

The verb phrase was tlus revealed as being particularly problentatic for these subjects.

\subsection{Norun Phrase}

- \#L displayed fiequent deteminer omsisions both in subject and object/adverbial position. This is congruent with a general pattern of "omission" that is also reflected in the high 
incidence of clause elcmenu. contula and auxiliary omissions displayed by \#L. She appears to be enuploying a strategy of omission of items which are semantically or perceptually less salient.

- The determiner errors produced by both subjects result largely from their failure to establish a contrast between definile and indefinite articles. Differentiation between contexts in which articles are obligatory, non-obligatory and obligatorily omitsed also poses difficulties for the subjects who insert determiners in inappropriate contexts. These errors may be the result of transfer as (tefinite and indelinite articles do not occur in African languages such as Zulu (Grant. 1987) and research shows that where the L2 learner's $L$ does nor make the same discriminations as the target language greater difficulty is experienced in learning those items than is the case for learners whose $L 1$ does make the semantic discrimination (Acl_aughlin. 1984, Zobl. 1984 cited in Towell and Hawkins, 1994)

- Detailed analysis of personal pronoun errors reveals that both subjects have failed to estabiish a contrast between the gender of pronouns. Once ayain this may be due to $\mathrm{Ll}$ transfer as masculine and feminine pronoun forms are not marked in African languages (Grant, 1987).

- Both subjects display numernus instances of incorrect selection of prepositions. This may also be the resuit of transter as English prepositions have no exact equivalent in African languages which use "locative forns altached to the noum: various class concords and a variety of multipurpose prepositional inflections and particles" (Grant, I987, p.200)

\section{DISCUSSION: FINDINGS OF FXTENDED ERROR ANALYSIS}

The extended analysis of the subjects' errors pernitted the identification of both idiosyncratic strategies and more general error patterns that characterise the interlanguage of both subjects in strikingly similar ways. This allowed for tentative hypotheses to be made regarding the nature and origin of errors idenified

However, there is a lack of "onichsus anm ny researchers regarding the origin of errors that are produced by $L 2$ learners and the role of the tirst hanguage in second language acquisition remains the topic of much detrals 
It was originally thought that a simple interference relationship existed whereby transfer from wi : 10 L2 syntactic structure resulted in error production. However, it is now widely genowledged that the relationship is more complex than this and can, at best, be considered grmbiguous (Duncan, 1989).

$\therefore$, iboth case studies and cross-sectional research indicate that the order of acquisition of syntactic and moiphological structures involves an imterplay of both developmental and transfer factors. Developmental factors include the universal cognitive mechanisms or strategies that are believed to guide both first and subsequent language acquisition (Dulay and Burt, 1974, Pienemans, 1989) accounting for relatively consistent sequences in the development of grammaticai morpholoyy and syntax that are evident in both monolinguals and second language learners for each language (McLaughlin, 1984; Duncan, 1989)

However, deviations from this order frequenly occur and variability is a recurrent theme in L2 acquisition research (Towell and Hawkins. 1994). In accounting for this variability many other factors have been identified as playing potentially inportant roles in L2 acquisition. These include both positive and negative Iransfer factors (Odlin, 1989), the effects of the frequency of occurrence (Larsen-Frecman, 1976) and perceptual salience (Pienemann, 1989) of structures it the inpul to which learners are exposed, context of learning and usage of the L2, the linited capacily nature of working memory (Mcl.aughlin, 1987 cited in Towell and Hawkins 1994) and the effects of explicil instruction and negative feedback (Schwartz, 1993 cited in Towell and Hawkins. 1904).

In addition. learners may simply adopt idinsyncratic "reduction" and "achievement" strategies (Faerch and Kasper, 1983) or differ in the leatures on which they focus attention in their atsemps to acsively construt their interlanguage

Thus, with the current state of theory and research, it remains extremely difficult to be certain of the type of error a learner is making and why they are making it as the same error can often be altributed either 10 iniralinglat or interlingual factors or the interaction of these factors (McLaughtin. 1984). An example from the present study would be the copula omission displayed by fiL. New $(10 \%+1)$ shace that in Alrican languages "copular constructions of the equivalence or atjicenal byse litupunly bave no manifestation of the copula" (p.310). This 
seems to indicate that \#L's slifliculties producing copular constructions in English may result from transfer from her $\mathrm{L}$ l. However, copula umission is also a recognised feature of early first language acquisition indicating that developmental factors may also be involved. In addition, the hypothesis made previously that \#L's linguage production is characterised by a general strategy of onission of perceptually and stmantically less salient items, provides an alternative explanation.

The above example indicates that error classification as undertaken there, cannot be considered an end in itself. It simply highlights aspecis of error production that warrant further investigation. Detailed "nicro-profiles" of als highlighted areas would be necessary for the description of the interlanguage to be considered truly comprehensive.

\section{PUASE 3: ANALYSIS OF VFRB ARGUMENT STRUC'TURE}

\subsection{Motivation}

Psevious analyses indicared that the acquisition of the verb phrase and its various components is particularly problematic fors tle subjects of this study In addition, both subjects displayed many errors in their realisations of the argument structures of lexical verbs. Fletcher (1992) believes that "knowiedge of verbs and their argunent structure is central to the syntactic organisation of the sentence and a deficit in this asea will considerably restrict communicative efficiency" (p. I.52)

Cursent theories suggest that vorbs are iejresented jevically at two separate levels. The participant or "thematic" roles involved in a verb's meaning are represented at a lexicalsemantic level (s-selection) while argument structure (c-selection) which constilues "the levical representation of grammatical information about a predicate" (Grimshaw, 1990, p 1) receives a separate ievical-syntactic representacion (Chomsky, 1986). The grammatical information referred to by Grimshaw (1990) relates to the syntactic complementation palterns which are realised in the predicate. 
In order for a chiid to learn about verb complementation patterns it is necessary that they acquire the mapping rules that link the verb's semantic properties and their syntactic complementation (Inylann, 1992)

3

However, a verb's c-selection is not always predictable from its s-selection. While, in English, onission of subject argunents is always ungranmatical (except in cases of ellipsis) the admissibility of altermations in certain predicate argument structures means that the omission pirect objects is lexically rescricted rather than constituting a regular gramnatical process (Ingham, 1992). Thus, children acquiring English have to learn, either verb by verb or as classes of verbs, whether each lexical verb takes one or more internal arguments and whether these are optional or obligatory (King, Sclielletter, Sinka, Fletcher and Ingham, in press).

Errors of verb argument strucure have not previously been discussed as characteristic of L2 'learners' interlanguage and! il was therefore decided to undertake a more detailed "microprofile" of verb-argument structure as advocated by Crystal et al (1989), based on the approaches astopted by Fietcher (1985) and King and Fletcher (1993)

\subsection{Summary of findings: Analysis of Verb Argument Structure}

In a study of the grammatical impairments displayed by children with Specific Language Impairment, Fietcher (1994) found that his subjects displayed etrors in predicate argument structure on $2 \%$ of the lexical verbs used (range in group studied: $0-7 \%$ ). This was considered to represent a significant problen for the children studied. In the present study $\#$ L produced errors in predicate argument structure on $38.57 \%$ of lexical verbs used and $\# D$ on $26.66 \%$ of verbs. Thus, although grevious research on $\mathrm{L} 2$ acquisition does not nention verb argument structure as presenting difitinties for L2 larners. lor the suljects of this study such errors are a widespread fcalure of their inlcrlanguag. 
Features of realisation of verl) arguncint structure noted include:

- Inconsistency in realisation of argument structure in different contexts

- Frequent omission of one predicate argument when verb required two or more, \#L more frequently omitred the NP while \#D displayed more frequent omissions of obligatory PPS.

- Confusion evident in \#D's syntactic realisation of arguments in that he substituted NPs for PPs and vice versa

- Inappropriate overgeneralisation of the argument structure of verbs that are similar in meaning. These errors may therefore reflect limitations in vocabulary selection or setrieval as the argument siructure sceins to have been selected by analogy to verbs that are lexically more precise than those that were in tact used.

- Both subjects frequently used "pro-verbs" (Rice. 1991 cired in Fletcher, 1992) that is

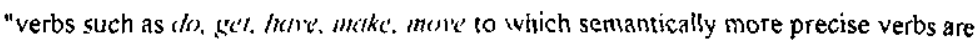
relatable as quasi-hyponyms" (p. 152) While this may simply reflect the limited vocabulary of the subjects, it has been hypothesised that overuse of these verbs by fanguage-jmpaired children could indicate difficulties in building accurate lexical representations for the semantically more precise verts or in deploying this knowledge within the "real-time demands of comversation" (Fletcher, (992, $\rho$ 152). More detailed investigation of boih comprehension and production of verhs with difterent types of argument structures is necessary in order for this hypothesis to be evaluated for L2 learners.

\section{DISCUSSION: FINDINGS OF VERU ARGIMENT STRUCTURE ANALYSIS}

Considering the previously discussed connlyesify of verb argument structure acquisition, it is not surprising that this task poses significant difficulties for L2 learners of English, particularly when transitivity and argument structure are realised ditferently in their native language. In African languages patterns if transitivity can be extremely complex, and relate to the structure of the clause as a whole rather than being primarily a function of the verb governing clause structure, as is the case in English (MaA, 1994) 
Whathresearch has recently hesun to emerge focusing on the processes involved in the gegfisition of lexical representations of verbs in first language acquisition (comprehensively weded by Ingham, 1993 and Fisher, 1904) Debate in this area centres around the question of whether children access the verb's syntactic structure via semantic data (eg. Pinker, 1989) of whether they deduce information about the verb's meanings by working back from the symtactic subcategorisation trames (ey Landau and Gleitnan, 1985 cited in Ingham, 1993). As pary of the errors in verb argument stricture displayed in the present study seem to involve an interaction of syntactic and semantic features, it is proposed that research into the acquisition of verb argument structure by 1,2 learners as well as more detailed investigation of the sernantic features of the errors they display, may provide new and valuable insights into this debate

9. IMPLICATIONS OF THE FINDINGS OF THIS STUDY

9.1 Development of tools for analysis

The use of the LARSP procedure in this study is felt to have been justified by the fact that it .. yielded a sufficientily detailed initial analysis of the subjects' interlanguages to allow for identification of pallerns of strength and weakness as well as areas that warranted further exploration

However, several limitations of this tonl there noted which proved significant in this study and indicate that the use of alternative or supplementary merhods of analysis should be considered in further research The major limitatıns identified include the following:

- LARSP fails to ditterentiate hetween complenents and adjuncts in predicate argument structure The L.ARSP atrals as theretore failed to identify the predicate argument structure errors displaved in this sudi. Perluaps a yrammatical approach which accounts for verb argumens struscuse with greater depht and precision. would be more appropriate for future analyses

- The limitations of the L.XK.SP's error classification procedure have been discussed (see Section ty The error analysis developed wh this study was specifically designed to account 
for the errors observed. Its usetitiness for other $L 2$ learners from the same population will therefore depend upon corroboration of the findings of this study. It is recommended that further evaluation and refinemenr of its callegories be undertaken.

- While LARSP provides comprehensive analysis of simple clause and phrase structure, it becomes increasingly limited as the language it is required to account for becomes more complex. Thus while it may be usefit tor analysis of the early interlanguages of $L 2$ leamers its usefulness may be limited as their proficiency increases.

\subsection{Linguistic investigation of interlanguage development}

- Large-scale descriptive studies as well as experimental designs are required to evaluate the accuracy and representativeness of the linguistic findings of this study and the hypotheses it generated

- A desired outcome of future researcli would be a comprehensive description of the process of second language acquisition undergune by indigenous language speakers learning English at a primaty school age in an educational setting Recognising that syntax constitutes only one dimension of language and that aspects such as phonology, semantics, pragmatics and discourse also require tirther investigation, it is felt that such comprehensive descriptions could be expected to yield information that would guide and enhance pedagogic interventions to facilitate language learning.

\section{CONCLUSION}

Athough it is acknowledged that it is not possible to generalise the results obtained on two case studies to a wider population, the fact that in this study two children of different gender, with differing language bach grounds (allhough) Zulu was considered to be L1 for both), attending different schools hut having had similar limited prior exposure to English, displayed such striking similatilies in the narure of their interlanguages, is felt to be significant. This exploratory study has highlighned numerous areas in which further research is required. Errors identified in verb argument structure, which have not been previously discussed by researchers in second language acquisition, are fels 10 he particular worthy of more extensive investigation. 


\section{REFERENCES}

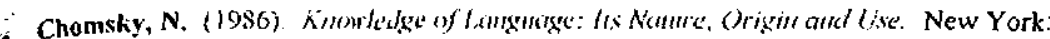
Praeger

-. Clahsen, H. (1985). Proliling second language development: A procedure for assessing . second language proficicncy. In K. Hyltenstaun and M. Pienemann (Eds.). Modelling

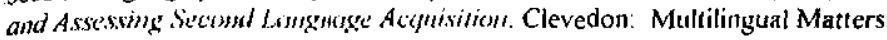

- Cole, P. R. (1982). Innguguge Disordersin Prowchon/ Children.

New Jersey: Englewood Cliffs

$\therefore$ Consolly, J. H. (1984). A conmentary on the LARSP procedure. British fommot of Disurters of (commumicatiom, 19,63-87

$\therefore$ Crystat, D. (1992). Mrofiling Lingmistic Lisubilisy (2ud Ect). London: Whurr

- Crystal, D., Fletcher, P. and Garmali, M. (1989). (itumnatical Analysis of Langmage Disability (2mal til). Londen: Wharr

- Cummins, J. (1976). The intluence of bilingualism on cognitive growth. A synthesis of research findings and explanatory hypotheses. Working Papers in Bilingmalism. 9, 1 - 43

- Cummins, J. (1991). Interdependence of first and second language proficiency in bilingual clildren. In E. Bialystok (Ed.). lamghtuge Processing in Bilingual Children. Cambridge: Cambridge University Press

- Dirven, R. (1904). Applicel Linguistics: Grammar. In R. E Asher (Ed.).

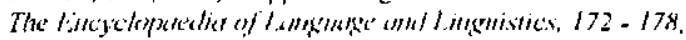
Oxford: Pergamon Press

- Dulay, H. and Burt, M, (1974). Natual sequences in child second language acquisition.

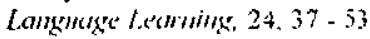

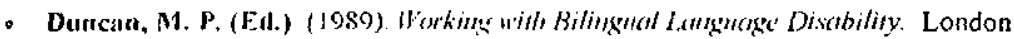
Chapnian Hall

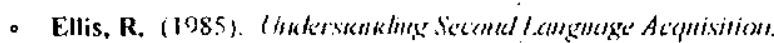
Oxford: Oxford Liniversity Press

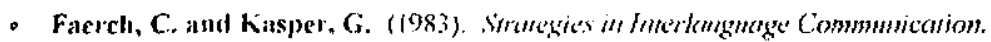
London: Longman

- Fisher, C. $\left.(19)^{6}\right)$. Struclute and meaning in the verb lexicon: Input for a syntax-aided

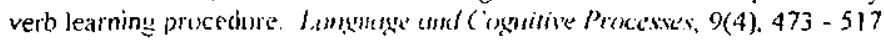


- Fletcher, P. (1955) $A$ ( $/$ h/ts Lermming of ling/inh. Oxford: Basil Blackwell

- Fletcher, P. (1992) l.exical verbs and language impairment: A case study.

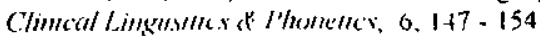

- Fletcher, P. (1994). Grammar and language impairment Clinical linguistics' as applied linguistics. In D. Graddol and J Swan (Eds). Licatuating Langunge: Popers from the

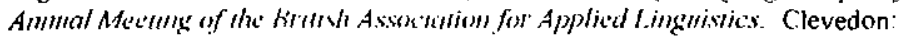
Multilingual Matters

- Grant, N. (1987) Swahili speakers In M. Swan and B. Smith (Eds.). Learner Eng/ish.

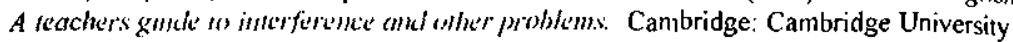
Press

- Grinishaw, J. (1990) Argmmen Swntmrs. Cambridge, M.A.: MIT Press

- Hawkins, P. and Spencer, H. (1085) Imirative versus spontaneous language assessment: A comparison of CELL and LARSP Bryish. Amrmol of Disorders of Conmmaicuiom, 20, 191 - 200

- Ingham, $\mathbf{R}$ (1992). Syntactic input and verb transitivity in first language acquisition Workmg Papers. Department of Lingevistic Science: L'niversity of Reading

- Ingham. R. (1993). Critical intluences on the acquisition of verb transitivity. In D. J.

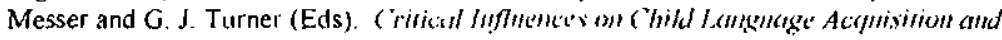
Developmest. London: MacMillan

- Jordaan, H. L. (1993) Language intervention to facilitate the acguisition of English as : second language by pre-school children. Unpublished Master of Arts Dissertation. University of the Witwatersrand, Johannesburg

- King, G. and Flerclier, P. (1993) Granmatical problems in school-age children with

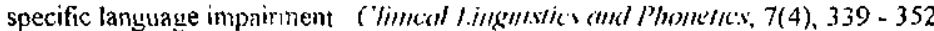

- King, G., Sclieltetter, C.., Sinka, I., Fletcher, P, and lugham, R. (In press). Englishspeaking children's knowledge of locative-contact and causative aiterations. Deparment of Linguistic Science. University of Reading

- Larsen-Freemin, D. (1976) An explanation for the morphente acguisition order of

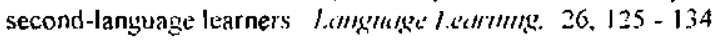

- Makoni, S. B. (1993). Mother tongue education. a literature review and proposed

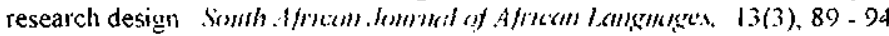

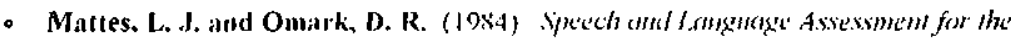
Bilinguat Hondretplyed. Califinmia College Hill Press

- Maw, J. (1994). Bantu Aanguages Syntax and morphology. In R. E. Asher (Ed.)

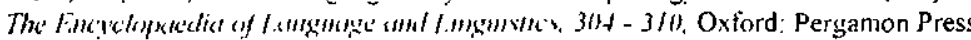




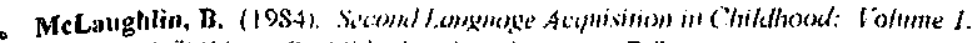

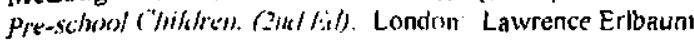

- McLaughlin, B. and Rubbins, S. (i494). Theory of second language learning and

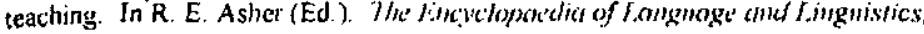
37+2-3752, Oxford: Pergamon Press

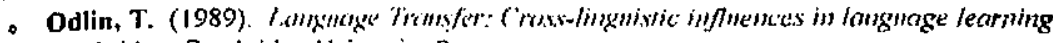
Cambridge: Cambridge Iniversity Press

- Pienenuanu, M. (1989). Is language teachable? Psycholinguistic experiments and hypotheses. Alydicaltimguristics, 1011), $52-79$

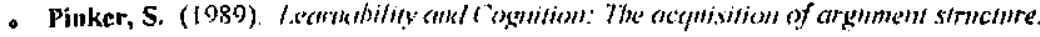
Cambridge, M.A.: MIT Press

- Quirk, R., Greeubauni, S., Leech, G. and Svartvik, J. (1985).

A Gromnter of Comempomory ling/isis. Harlow: Longman

- Selinker, L. (1972). Interlangnage. Im/rommionol Review of Applied Linguistics, $\mathrm{X}$, $209-230$

- Towell, R. and Hawkins, R. (1994). Approtethes es Secomd lemgnage Acipmivition. Clevedon: Multilingual Matters

- Van Kleeck, A. and Riclaardsou, A. (1988). Language Disorders: Language delay in the child. In N. Lass, L. McReynolds, J. Northern and D. Yoder (Eds.). Hamblhook of

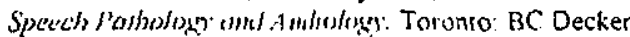

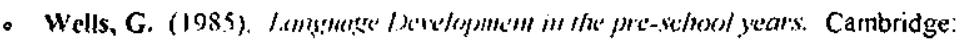
Cantoridge Lniversity Press 
APPENDIX 1: SUBJECT IPESCRIPTION

\begin{tabular}{|c|c|c|c|}
\hline & SUBJECT L & SUBJECT D & $\begin{array}{l}\text { SOURCE OF } \\
\text { INFORMATION }\end{array}$ \\
\hline$\widehat{A G E}$ & 7 yss $1 \mathrm{mth}$ & 6 yrs 8 mths & Casc History Form \\
\hline GENDER & Female & Male & As above \\
\hline $\begin{array}{c}\text { EARLY HISTORY } \\
\text { AND } \\
\text { DEVELOPMENT }\end{array}$ & Nomnal & Normal & $\begin{array}{l}\text { As above + } \\
\text { interview with } \\
\text { caretaker }\end{array}$ \\
\hline $\begin{array}{l}\text { CURRENT } \\
\text { PHYSICAL, } \\
\text { SOCIAL AND } \\
\text { COGNITIVE } \\
\text { ABILITIES }\end{array}$ & Satisfactory & Satisafactory & $\begin{array}{l}\text { Teacher } \\
\text { questionnaire and } \\
\text { interview }\end{array}$ \\
\hline $\begin{array}{c}\text { LANGUAGE } \\
\text { BACKGROUND }\end{array}$ & $\begin{array}{l}\text { L1: Zulu } \\
\text { Other languages } \\
\text { spoken: Sotho, Tsonga } \\
\text { (limited proficiency) } \\
\text { Limitcd exposure: } \\
\text { English }\end{array}$ & $\begin{array}{l}\text { L1: Zulu } \\
\text { Limited exposure: } \\
\text { Afrikaans, English }\end{array}$ & $\begin{array}{l}\text { Language } \\
\text { Background } \\
\text { Questionnairc and } \\
\text { interview with } \\
\text { caretaker }\end{array}$ \\
\hline $\begin{array}{c}\text { FIRST } \\
\text { LANGUAGE } \\
\text { PROFICIENCY }\end{array}$ & Developing normally & Developing normally & $\begin{array}{l}\text { Bilingual Oral } \\
\text { Language } \\
\text { Development } \\
\text { (B.O.L.D.) mcasure } \\
\text { completed by } \\
\text { caretaker and } \\
\text { caretaker intervicw }\end{array}$ \\
\hline $\begin{array}{l}\text { EXPOSURE TO } \\
\text { ENGLISH }\end{array}$ & $\begin{array}{l}\text { English medium pre- } \\
\text { school-1 yr, English } \\
\text { medium primary } \\
\text { school-3 mths }\end{array}$ & $\begin{array}{l}\text { English medium pre- } \\
\text { school-1 yr, English } \\
\text { medium primary } \\
\text { school-3 mths }\end{array}$ & $\begin{array}{l}\text { Case History Form. } \\
\text { Language } \\
\text { Background } \\
\text { Questionnaire and } \\
\text { caretaker intertiew }\end{array}$ \\
\hline $\begin{array}{c}\text { ENGLISH } \\
\text { PROFICIENCY }\end{array}$ & Limited & Limited & $\begin{array}{l}\text { B.O.L.D. measure } \\
\text { completed by class } \\
\text { teacher }\end{array}$ \\
\hline
\end{tabular}

It was necessary to establish that subjects were functioning normally in their first language. to rulc out the possibility that any difficulties displayed in acquisition of the $L 2$ were the result of underlying lingtisstic disability. In the absence of language assessment tools in the home language of subjects it wis nccessary to rit. on information provided by caretakers. The Bilingual Oral Language Development (B.O.L.D.) incasure (Matc: and Omark, 1984) as modified by Jordaan (1993) was used which probes usage of a range of communicativc: functions and conversational management strategies. To enable the carctakers to complete the questiomairc. all example of each type of language behaviour was given. However, in case the B.O.L.D. was not sufficiently sensitive to identify more subtle language problems, additional questions suggested by Colc (1982) regarclin: the subjects' LI grammar and vocabulary were included (Jordaan, 1993). Teachers were aiso asked to compleic the B.O.L.D. questionnaire regarding the children's use of English as a comparison 
APPENDLX 2:

\section{GLOSSARY OF SYMBOLS USED IN LARSP PROCEDURE \\ (Crystal, Fletcher and Garman, 1989)}

\begin{tabular}{|c|c|}
\hline$A$ & adverbial \\
\hline Adj & adjectival \\
\hline Aux m & modal auxiliary \\
\hline Auxo 0 & other auxiliary \\
\hline aus & contracted auxiliary form \\
\hline $\bar{c}$ & coordinator \\
\hline $\mathrm{c}$ & complement \\
\hline Comm & command sentence type \\
\hline $\operatorname{conn}$ & connectivity marker \\
\hline $\operatorname{cop}$ & copula \\
\hline 'cop & contracted copula form \\
\hline D & determiner \\
\hline Det & determiner system (errors) \\
\hline ed & past tense \\
\hline en & past participle \\
\hline er & comparative \\
\hline est & superlative \\
\hline gen & genitive \\
\hline $\mathbf{I}$ & initiator \\
\hline -ing & present participle \\
\hline Int & intensifier \\
\hline let & first person command \\
\hline$-1 y$ & adverb marker \\
\hline Major & $\begin{array}{l}\text { a major sentence whose elements are able to combine with } \\
\text { other elements according to the language's grammatical } \\
\text { rules, to produce an indefinitely large set of sentences } \\
\text { (Crystal, 1992, p.17) }\end{array}$ \\
\hline Minor & $\begin{array}{l}\text { non-productive minor sentence patterns that do not readily } \\
\text { allow an analysis into structural types (Crystal, 1992, p.17) }\end{array}$ \\
\hline $\mathbf{N}$ & noun \\
\hline$" \mathrm{~N} "$ & noun-like element at Stage I \\
\hline N Irreg & irregular noun inflections (errors) \\
\hline Neg & negation \\
\hline
\end{tabular}


n't

o

Od

Oi

part

$P$

pl

postmod

clause

postmod

phrase

Pr

Pron o

Pron p

Q

"Q"

Quest

$\mathbf{s}$

S

$+S$

$\mathrm{T}$

V

" $\mathrm{V}$

$V$ irreg

Voc

$\mathrm{X}, \mathrm{Y}, \mathbf{Z}$

3s

$\rightarrow$ contracted negative form

object

direct object

indirect object

particle

pupil or patient

plural

postmodifying clause

postmodifying phrase

preposition

other pronoun

personal pronoun

question-word

Stage I question-word

question sentence type

subordinator

subject

expressed subject in a command

teacher or therapist

main verb (at phrase-structure level)

verb

verb-like element at Stage I

irregular verb inflections (errors)

vocative

cover symbols for elements of structure

third person singular

word order 


\section{APPENDIX 3}

\section{DESCRIPTION OF ERROR CATEGORIES: \\ EXTENDED ERROR ANALYSIS}

(adapted from Crystal, 1992; King and Fletcher, 1993)

\section{$1 ; \cdot$ Connectivity}

CÖNN ERR: and - inappropriate use of and e.g. he broke his amm and the ladder slipped CONN ERR: $\mathrm{c}$ - inappropriate use of other connectives e.g. he broke his arm but the ladder slipped

CONN ERR: s - inappropriate use of subordinating markers e.g. the ladder slipped because febroke his arm

CONN ERR: other - inappropriate use of other items as connectives e.g. she is wearing a

$\therefore$ iblue hat and then white gloves

\section{Clause Elements}

NULL S - Subject omitted in obligatory context (non-ellipticai) e.g. is happy

NULL $\mathbf{O}$ - Object omitted in obligatory context e.g. he put on the table

NULL A - Adverbial omitted in obligatory context e.g, he gave the ball

ORDER ERR - incorrect word order e.g. chased the man the dog

CONCORD ERR - failure of the subject to agree in number with another element e.g. they is running, he hurt themself

\section{Verb Phrase}

NULL COP - copula omitted e.g. the boy sad

COP ERR - incorrect form of copula used e.g. he be sad

NULL AUX - auxiliary (modal or other) omitted e.g. the girl swimming AUX M ERR - errors of substitution or order involving modal auxiliaries e.g. he must (="can") jump, he jump can

AUX O ERR - errors of substitution or order involving other auxiliaries e.g. he be going, he going is

AUX INSERT - auxiliary inserted inappropriately e.g. he is came

NULL ING - omission of the progressive morpheme in contexts where progressive aspect clearly intended e.g. the girl was run when she fell

NULL 3s - Third person singular morpheme omitted (only instances where present tensc clearly indicated are counted as NULL 3s, if any doubt exists as to intended tense or aspect counted as UVF error) e.g. the boy want ice-cream now 
UVF - uninflected verb form - base form of verb stem used without inflection e.g. she run across the road

PROGR ERR - progressive aspect used inappropriately e.g. she was shutting the door

TENSE ERR - inappropriate marking of tense e.g. he is cutting the trees (referring to past event). Uninflected verb forms are not marked for tense and are therefore not counted as errors of tense

VREG ERR - incorrect form of regular verb used e.g. singinging, I walken V IRREG ERR - incorrect form of irregular verb used e.g. tooken, wented

\section{Noun Phrase}

NULL DET - determiner omitted e.g. girl eats the apple, the girl eats apple DET ERR: POSS PRON - incorrect possessive pronoun selection resulting in errors of gender or number e.g. he wants to eat her own ice-cream

DET ERR: ORDER - determiner in incorrect position in noun phrase e.g. man the came DET ERR: OTHER - incorrect form of determiner used (excluding possessive pronoun errors) e.g. I want $a$ milk

DET INSERT - inappropriate determiner inserted e.g. he's going to the school

PRON P ERR: GENDER - personal pronoun ertor, incorrect gender e.g. she is coming (referring to a male person)

PRON P ERR: CASE - personal pronoun error, incorrect case used e.g. him is coming

PRON P ERR: OTHER - any other error involving personal pronouns

e.g. we are coming (when in context "they" is appropriate)

PRON P INSERT - inappropriate insertion of a personal pronoun

e.g. the boy he runs

PRON O ERR - all other pronoun ersors e.g. I want anything

PREP ERR - use of incorrect preposition e.g. put the milk in the table

NULL PREP - preposition omitted e.g. put the milk the table

PREP ORDER - preposition in incorect position e.g. put the milk the table on

N REG ERR - Incorrect plural form of a regular noun e.g. boyses

N IRREG ERR - Incorrect plural form of an irregular noun e.g. mouses, sheeps 